\title{
An Evaluation of the Implementation of a Court Outreach Program for People With Severe and Persistent Mental Illness Who Are Legally Involved
}

\author{
John Sylvestre, Tim Aubry, and Jaclynne Smith \\ University of Ottawa \\ Todd Bridger \\ Canadian Mental Health Association
}

\begin{abstract}
This paper describes an implementation evaluation of a Court Outreach Program that provides outreach and community-based treatment and support to people with mental illness in the legal system. The paper describes the Court Outreach Program and presents evaluation findings. Program strengths included competent and knowledgeable court outreach staff who contribute to the legal and mental health systems and provide access for clients to a range of community supports and treatments. Challenges included a limited program capacity to serve all potential clients and bottlenecks in the intake/assessment process. Recommendations are made to improve the implementation of the program.
\end{abstract}

John Sylvestre, Tim Aubry, and Jaclynne Smith, School of Psychology and Centre for Research on Educational and Community Services, University of Ottawa, Ontario; Todd Bridger, Canadian Mental Health Association, Ottawa Branch.

Funding for this research was provided by the Ontario Ministry of Health and Long-Term Care and the Ontario Mental Health Foundation. We gratefully acknowledge the significant help provided by the managers, outreach workers, and administrative staff at the Canadian Mental Health Association, Ottawa Branch, with data collection for the study. We also thank clients, family members, key informants, and staff of the Court Outreach Program for their participation.

Correspondence concerning this article should be sent to John Sylvestre, School of Psychology, University of Ottawa, 125 University Pvt., Room 416A, Ottawa ON K1N 6N5. E-mail: jsylvest@uottawa.ca 
Court outreach programs are community support programs for people with severe mental illness who are involved with the legal system. This paper describes an evaluation of the implementation of a Court Outreach Program offered by the Ottawa Branch of the Canadian Mental Health Association (CMHA Ottawa). The evaluation was conducted under the auspices of the Systems Enhancement Evaluation Initiative (SEEI). SEEI was funded by the Ontario Ministry of Health and Long-Term Care to evaluate the effects of the significant investments in the community mental health system made by the Government of Ontario over 4 years, beginning in 2004/05. Investments were made in four areas: (a) crisis services, (b) intensive case management, (c) assertive community treatment programs and early intervention in psychosis, and (d) services for individuals with mental illness who are in contact with the criminal justice system. The Court Outreach Program received funding as a result of these investments, enabling it to increase its service capacity.

This paper describes findings from an implementation evaluation that was conducted as part of the SEEI. First, it provides a review of the literature on legal system diversion programs. The review will help to distinguish the critical features of this Court Outreach Program from other mental health interventions in the legal system. The paper then describes the CMHA Ottawa's Court Outreach Program and presents findings from an evaluation of the implementation of this program. The paper concludes by presenting recommendations for improving the implementation of court outreach programs.

\section{LEGAL SYSTEM DIVERSION PROGRAMS}

Steadman, Barbera, and Dennis (1994) defined legal system diversion programs as

specific (formal or informal) programs that screen defined groups of detainees for the presence of a mental disorder; use mental health professionals to evaluate all those detainees identified in the screening; and negotiate with prosecutors, defence attorneys, community-based mental health providers, and the courts to produce a mental health disposition outside the jail in lieu of prosecution or as a condition of a reduction of charges (whether or not a formal conviction occurs). (p. 1110, italics in original)

Although there are a variety of types of diversion programs, they all share the common assumption that people with serious mental illness are better served by the mental health system than by the criminal justice system (Boccaccini, Christy, Poythress, \& Kershaw, 2005; Draine, Blank, Kottsieper, \& Solomon, 2005). Legal system diversion programs differ in terms of the timing of the diversion. Pre-booking diversion avoids the laying of charges against individuals by enabling police officers to make referrals to appropriate treatment programs (Draine et al., 2005). Post-booking diversion (also known as pre-trial diversion) diverts people after they have been booked for a crime, but before trial (Boccaccine et al., 2005; Draine et al., 2005; Hartford, Carey, $\&$ Mendonca, 2007). Both types of programs operate on the basis of collaborative agreements between the criminal justice system and mental health agencies or programs (Boccaccini et al., 2005). Typically, these programs divert individuals for minor, non-violent offences. Participation in these programs is voluntary on the part of the client, and also requires assent from the prosecution, the defence, and the court (Boccaccini et al., 2005; Hartford et al., 2007).

The mental health services to which individuals are diverted can vary from clinicians located in the court who assist with assessment and facilitate referrals in the community, to case managers who take on responsibility for diverted clients as part of their caseloads (Lattimore, Broner, Sherman, Frisman, \& Shafer, 
2003). At the heart of many court outreach programs, including the one that is the focus of this evaluation, are intensive case management services. Intensive case management provides individualized services that focus on client identification, outreach, direct services, service planning, linkages to other services, and client advocacy (Steadman, Morris, \& Dennis, 1995). These programs are intended to benefit individuals through access to treatment and supports, and to reduce the need for legal and treatment systems (Boccaccini et al., 2005).

Mental health courts are a form of court diversion that typically takes place in courts post-plea (Steadman et al., 1995). Common features of mental health courts are court dockets focused exclusively on cases involving people with serious mental illness and adjudication through non-adversarial proceedings. Additionally, participation in mental health courts is voluntary (Boccaccini et al., 2005; Christy, Poythress, Boothroyd, Petrila, \& Mehra, 2005; Redlich, Steadman, Monahan, Robbins, \& Petrila, 2006).

\section{The Implementation of Legal Diversion Programs in Ontario}

Hartford et al. (2004) identified 18 legal diversion programs in Ontario, distributed throughout the province. Hartford, Carey, and Mendonca (2007) attributed the increasing prevalence of legal system diversion programs to the criminalization of people with serious mental illness. This criminalization is explained by the process of deinstitutionalization in Canada that led to the increased presence of people with serious mental illness residing in the community with inadequate community-based treatment, along with policing practices that led to an increased probability that people with mental illness would be charged with minor offences (Hartford et al., 2007).

Despite the increasing presence of legal diversion programs in Canada, there has been little research published on these Canadian programs. The most recent study of these programs in Ontario was conducted by Dewa and colleagues (2008) as part of "The Matryoshka Project," a 3-year study that examined programs created through the Ontario Ministry of Health and Long-Term Care's investments in the mental health system. The study provided a snapshot of six legal diversion programs in the province of Ontario. The CMHA Ottawa Court Outreach Program was not included in this sample. The study found that the majority of clients of these programs were male, less than 39 years of age, and had never been married. The clients had low levels of educational achievement and low rates of employment. Most had received a diagnosis of schizophrenia, and over one third had a concurrent disorder.

Findings also demonstrated the wide range of services offered by court support case managers. In addition to providing consultations to potential clients (about $22 \%$ of their time), these case managers consulted with a number of figures both within the court system (e.g., defence lawyers, crown attorneys, and police

officers) and outside of it (e.g., family members, and staff of community partners and agencies). At the same time, Dewa et al. (2008) found that these services had reached their capacity and had limited ability to admit new clients.

\section{DESCRIPTION OF CMHA OTTAWA'S COURT OUTREACH PROGRAM}

The Court Outreach Program at CMHA Ottawa is a post-booking, or pre-trial, program to which people with serious mental illness are referred when they become involved in the legal system. Most, but not all, 
clients are diverted from the legal system. The service was funded by the Ontario Ministry of the Attorney General in 1995 in response to the work of a local Human Service and Justice Coordinating Committee. The committee had been struck to examine the plight of homeless individuals with serious mental illness who were inappropriately coming into contact with the criminal justice system.

Prior to 2005, staffing for the service was limited to 2 FTE (full-time equivalent) court outreach workers. These workers served up to 60 clients per year. In May 2005, the program received enhanced funding from the Ontario Ministry of Health and Long-Term Care, resulting in an increased capacity of 1 FTE intake/ assessment worker, 2 FTE court outreach workers (for a total of 4 FTE outreach workers), a 0.5 FTE extendedhours support worker, and 2 FTE case managers. The increased funding also enabled the CMHA to add 1.5 FTE community mental health and addiction workers to work with CMHA clients, including those in the Court Outreach Program. The increased staffing was planned to increase capacity to 120 clients served per year through outreach services and 24 clients supported longer term by services provided by case managers.

The primary objectives of the program are (a) to support individuals during their interactions with the courts, (b) to ensure clients can access and maintain the community housing of their choice, and (c) to address psychosocial community rehabilitation needs of clients. The intended implementation of the program is presented in Figure 1. The model depicts the primary programmatic activities and the flow of clients into and through the program.

\section{Intended Clientele}

A primary goal of the program is to connect individuals involved with the legal system with mental health services. Thus the intended clients are people with serious mental illness who will benefit from communitybased mental health services. Because of the program's limited capacity, individuals who are assessed as requiring more intensive community supports are prioritized over people who require less support. As in most legal diversion programs, participation is voluntary.

\section{Referrals and Assessments}

As depicted in the program model, the first step is referral. Referrals can be received from a wide range of sources, including the Crown office, duty council, defence lawyers, probation and parole officers, police, family, corrections, other community programs, and psychiatric forensic programs. Referrals are assessed by an intake/assessment worker to determine appropriateness for the program. The intake/assessment worker is also expected to provide on-site support at the courthouse to co-workers and court personnel, and brief interventions with individuals in the court system. Individuals who are assessed as not requiring intensive support are given information and referrals to other suitable programs. Those who are appropriate are assigned to a court outreach worker.

\section{Court Outreach Workers and Community-Based Support}

The majority of the court outreach services are delivered by a primary worker in the context of a oneto-one relationship with the client. Court outreach workers carry caseloads of approximately 15 clients at a time. Services are usually short term (i.e., 7-12 months). The worker is expected to perform a variety 
EVALUATION OF THE IMPLEMENTATION OF A COURT OUTREACH PROGRAM

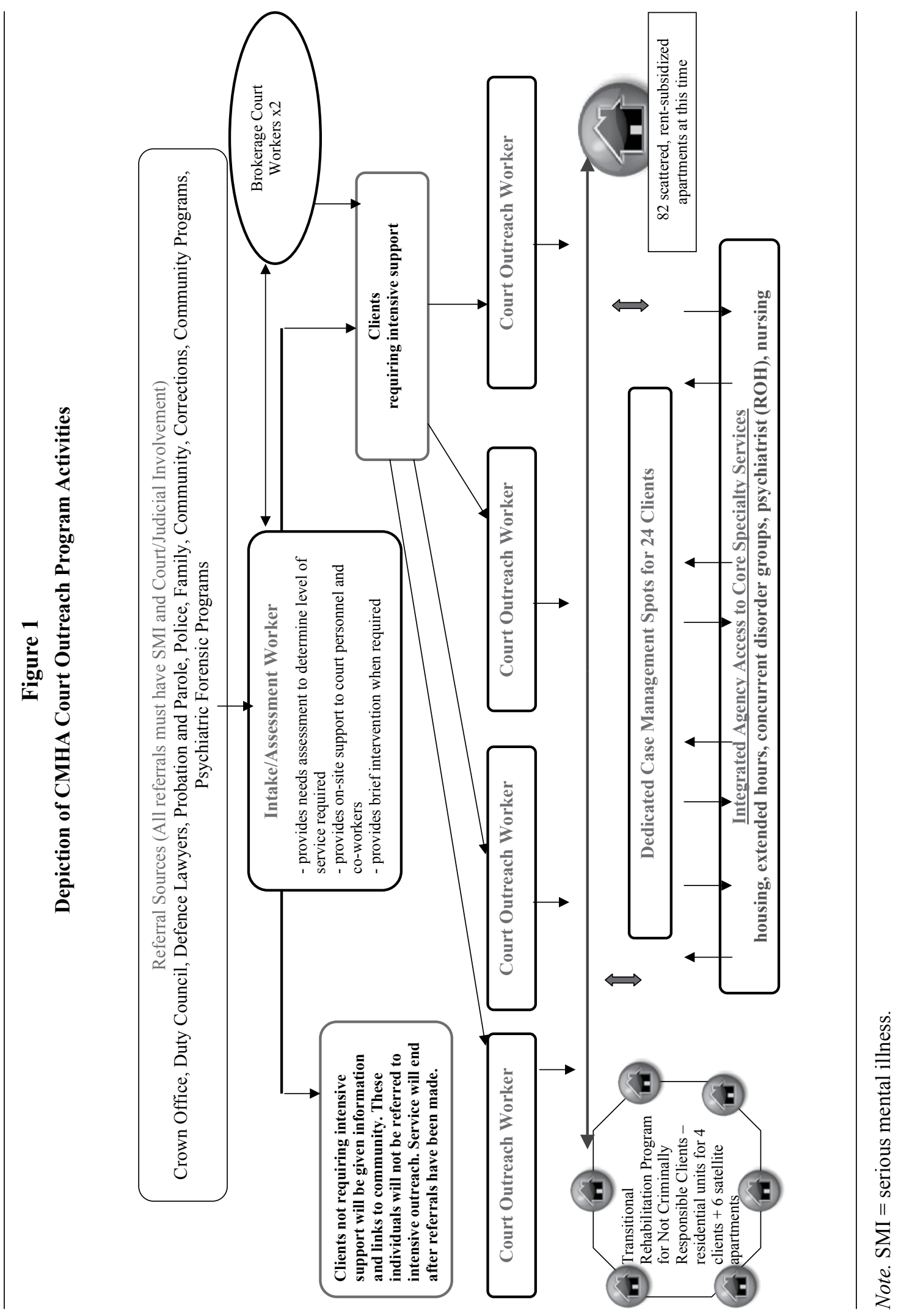


of functions, including assertive outreach, therapeutic relationship building, client and systems advocacy, symptom management, life-skills teaching, supportive counselling, family support, and crisis intervention. Court outreach workers also help clients to secure financial support and access to affordable housing through the CMHA Ottawa's housing first program.

Clients of court outreach services are expected to have access to the range of multidisciplinary treatment provided by CMHA Ottawa, including an in-house psychiatrist, registered nurses, an occupational therapist/ employment specialist, a recreational therapist, and community mental health and addiction workers who facilitate concurrent disorders treatment groups. In addition, clients should be able to access on an as-needed basis rental housing units or rent supplements, and support in the evening hours and on weekends.

\section{EVALUATION OF THE PROGRAM IMPLEMENTATION}

The current implementation evaluation was conducted in conjunction with an outcome evaluation. Findings from this outcome evaluation are reported in this special issue by Aubry, Sylvestre, Smith, Pettey, and Smith. Implementation evaluations are conducted to identify the program theory behind an intervention and determine if the program is being implemented to the targeted population as intended (Rossi, Lipsey, \& Freeman, 2004). An Evaluation Advisory Committee was established to provide oversight of the evaluation. The committee was made up of senior managers and a board member from CMHA Ottawa, representatives from the legal community, and a family member. The evaluation team consisted of two investigators, a project coordinator, and research assistants. The evaluation team was located at the Centre for Research on Educational and Community Services at the University of Ottawa.

In a review of the literature on court diversion programs, Hartford et al. (2007) noted that these programs vary considerably in their structure and operations. Hartford and her colleagues identified only a small number of published studies of these programs, and only one study examined a program located in Canada (Swaminath, Mendonca, Vidal, \& Chapman, 2002). Given the limited description and evaluation of these programs in general, and more specifically in Canada, a detailed evaluation of the implementation of this well-established program will provide useful information and directions for the implementation of similar programs elsewhere.

We employed quantitative and qualitative data to answer three questions:

1. Is the Court Outreach Program being delivered to the intended population?

2. Is the Court Outreach Program being implemented as planned?

3. What are the perceived strengths and weaknesses of the Court Outreach Program?

The evaluation was based on assessment of the relationship between the intended program, as described above, and data on the actual implementation of the program. Quantitative data were used to provide an objective assessment of who was admitted to the program and what services they received; qualitative data were collected to assess and to contrast the perspectives of different stakeholders on program implementation. Much of these qualitative data are from CMHA staff and managers as they had the most experience and the broadest perspective on this program. Their perspectives may be influenced by their personal and professional associations and investments in the program. 


\section{METHODS}

Table 1 includes the questions guiding the implementation evaluation and the corresponding methods that were used to answer these questions. The research was approved by the Research Ethics Board at the University of Ottawa. All participants who were sources of primary data in the study provided informed consent. The particular processes through which consent was obtained are described for each source of data.

\section{Table 1}

Evaluation Questions and Methods for the Implementation Evaluation

\begin{tabular}{|c|c|}
\hline Evaluation question & Methods \\
\hline $\begin{array}{l}\text { 1. Is the Court Outreach Program being delivered } \\
\text { to the intended population? }\end{array}$ & $\begin{array}{l}\text { - Secondary analysis of administrative data collected on } \\
\text { consumers } \\
\text { - Focus groups with program staff } \\
\text { - Key informant interviews }\end{array}$ \\
\hline $\begin{array}{l}\text { 2. Is the Court Outreach Program being } \\
\text { implemented as planned? }\end{array}$ & $\begin{array}{l}\text { - Key informant interviews } \\
\text { - } \text { Focus groups with program staff } \\
\text { - Second interviews } \\
\text { delivered analysis of data collected on services }\end{array}$ \\
\hline $\begin{array}{l}\text { 3. What are the perceived strengths and } \\
\text { weaknesses of the Court Outreach Program? }\end{array}$ & $\begin{array}{l}\text { - Key informant interviews } \\
\text { - Focus groups with program staff } \\
\text { - Client interviews }\end{array}$ \\
\hline
\end{tabular}

\section{Participants}

A variety of program stakeholders participated in the evaluation. They included CMHA program managers, court outreach workers, and other personnel familiar with the program $(n=20)$; key informants from the Ottawa legal system including judges, defence attorneys, and crown prosecutors $(n=8)$; family members of clients $(n=3)$; and clients $(n=8)$. In addition, secondary data on the demographic and clinical profiles of 95 clients were analyzed.

\section{Data Collection}

Focus groups. Three focus groups were conducted with CMHA managers, court outreach workers, and other CMHA staff members. Each focus group included 6 to 8 participants. They discussed their experiences with the program, including their perceptions of the client population and the intended and actual implementation of the program. They also provided recommendations for improving the program. The focus groups were conducted by a study investigator, and handwritten notes were taken by a research assistant. In addition, the focus groups were audio recorded.

Interviews. Interviews were conducted with three groups of participants: key informants, family members, and clients. Interviews with key informants were conducted over the telephone and focused on their 
impressions of the program and its impact on the court system. Key informants were people in the judicial system who had had contact with CMHA's Court Outreach Program, including judges, lawyers, forensic psychologists, and other outreach workers. They were identified by CMHA managers, as well as through a visit to the courthouse by one of the researchers. Consent forms were sent to the key informants electronically. The interviewers reviewed the consent form including issues concerning confidentiality, participation, and procedures, and obtained verbal consent. Interviewers recorded the telephone sessions in handwritten notes, which were transcribed into electronic files for analysis.

Interviews with family members were also conducted by telephone by the study investigators and a research assistant. The family members were identified by workers and clients in the Court Outreach Program. Copies of the consent forms were sent to participants through the mail. The interviewer verbally explained the consent forms, participation, procedures, and confidentiality issues, and obtained verbal consent. Family members were asked questions about their impressions of the program based on their experiences with it and those of their family member. Detailed handwritten notes were taken during the interviews that were then compiled in electronic files for analysis.

Interviews were conducted in person with clients. CMHA outreach workers accompanied their clients to interviews and introduced them to the interviewer, but did not stay during the interview. The one-to-one interviews were conducted by research assistants and by the project coordinator. Consent forms were reviewed with the participants, who signed the forms prior to the start of the interviews. Clients received a $\$ 10$ honorarium for their participation. The interviewers recorded the session in handwritten notes, which were then transcribed by another researcher. Clients were asked about their impressions and experiences with the program and, in particular, the services they received from their outreach worker.

\section{Analyses of Qualitative Data}

The qualitative data were analyzed in the following steps. The project coordinator transcribed recordings of the focus groups with CMHA staff members, managers, and court outreach workers. The project coordinator then worked with a senior researcher to inductively generate an initial set of codes. This process involved identifying, grouping, and labelling similar statements made by the participants (Strauss, 1987). Through a method of continuous comparison of the emerging categories in the data, a preliminary set of categories were developed and defined. Categories were first identified for program goals, client eligibility criteria, referral processes, assessment processes, expected and actual implementation, challenges, strengths, weaknesses, and recommendations. Then, where appropriate within these larger categories, subcategories were developed to further organize the data. At this point, a second research assistant was asked to review the coding scheme and to apply it to the same focus group transcripts. This process confirmed that the initial codes reflected the data and also helped to further refine and clarify a number of the categories.

This coding scheme was then used to analyze data from the interviews with family members, clients, and other key informants. The research team used the existing categories and took note of other possible themes that were unique to these other groups. Few new categories were identified in this analysis, likely due to the similarities in the interview questions for each of the groups. 


\section{Secondary Analyses of Program Data}

Data on demographic and clinical characteristics of 95 clients, as well as the amount of time and number of contacts associated with different services delivered to clients by CMHA staff, were accessed for analysis from the Client Record Management System (CRMS), a computerized administrative database used by CMHA Ottawa. This database includes variables from the Canadian version of the "PSR Toolkit" (Ontario Federation of Community Mental Health and Addiction Programs, 1999). CMHA staff collect these data for each client as soon as possible after entry into the Court Outreach Program. These clients had been admitted into the program between August 31, 2005, and February 28, 2007, and had received at least 3 months of service. Of this sample, 50 were still active in the program and 45 had terminated their involvement. A copy of the database was stripped of personal identifiers and provided to the evaluation team for analysis. Data analysis consisted primarily of descriptive analyses.

\section{FINDINGS}

This section presents findings from the evaluation of the implementation of the Court Outreach Program. The section is organized according to the evaluation questions outlined in Table 1. Key program components and corresponding findings are presented in Table 2.

Table 2

Summary of Program Components and Evaluation Findings

Clientele

- People with serious mental illness who are involved with the legal system and who will benefit from community-based mental health services

Referrals and assessments

- Referrals are received from a wide variety of sources

- Referrals are assessed by intake/assessment worker

- Intake/assessment worker provides on-site support at courthouse to court personnel and potential clients

Court outreach workers and community-based support

- Court outreach services are delivered one-to-one to clients

- Court outreach workers provide direct support and access to a variety of services within and external to the CMHA
- Program serves a largely male, single population with serious mental illness, of whom almost half have a psychotic disorder and almost three quarters have a concurrent disorder

- Program serves clients who have a range of psychosocial needs and diminished functional ability

- Potentially an underreferral of clients to the program due to perceptions of limited program capacity

- Challenges in assessment/intake process arising from confusion among clients, difficulties in assessing needs, and a lack of information

- Intake/assessment worker provides a range of supports to court personnel

- Services provided from a client-centred perspective

- Court Outreach Program integrated within CMHA providing access to a wide range community-based services and supports

- Some challenges accessing supports and services outside of CMHA

- Clients provided support to navigate court system 


\section{IS THE COURT OUTREACH PROGRAM BEING DELIVERED TO THE INTENDED POPULATION?}

\section{Quantitative Findings}

Demographic characteristics. Almost three quarters (74\%) of the clients were male. The clients ranged in age from 18 to 59 years old, with an average age of 34 years old. Almost all of the clients (98\%) were single. Over half of the clients $(60 \%)$ had not completed high school and $16 \%$ had received post-secondary education at a college or university. Only a small percentage (10\%) were identified as working or involved in a vocational training program at program entry.

Clinical characteristics. Almost one half (47\%) of clients had a primary diagnosis of schizophrenia or other psychotic disorder. The other most common diagnosis was mood disorder (39\%). Almost three quarters (71\%) were described by their outreach workers as having a concurrent disorder. At intake, almost all clients $(95 \%)$ were assessed by their workers as having housing problems.

Legal status. A majority of clients (70\%) had multiple charges laid against them, and almost one third (32\%) had five or more charges brought against them. Almost one half of the clients $(47 \%)$ had been charged with assault prior to entering the program. The next most common preadmission charge was failure to comply with court orders $(30 \%)$, followed by uttering threats $(28 \%)$, theft $(22 \%)$, breach of condition (20\%), and mischief (17\%).

\section{Qualitative Findings}

Stakeholder perceptions of eligibility criteria. There was little confusion and few discrepancies among participants in terms of perceptions of program eligibility. These perceptions reflected the criteria outlined in the program model. Participants identified three categories of program eligibility criteria: legal problems, personal characteristics, and inadequate psychosocial supports.

Participants agreed that being involved with the legal system, and more specifically being charged with a crime, was a prerequisite for admission to the program. Some participants noted the importance of admitting those who had been charged several times and who had had several appearances before the court. One CMHA manager said, "I can think of some cases of people we've picked up who were quite frequently ... in the court system, and they were able to move out."

Participants identified three personal characteristics that qualified people for the program. First, there was agreement that individuals referred to the program should have a serious mental health issue. Some participants noted that a prior formal diagnosis was not required for admission to the program if the mental health problem was evident. Clients and family members acknowledged the presence of mental health problems, most commonly schizophrenia, at the time of admission. Second, CMHA staff and key informants pointed to a diminished level of functional ability as a requirement for admission to the program. This included problems in planning, keeping appointments, taking medications, or meeting the demands of everyday life. Third, participants identified the presence of a concurrent disorder or complex needs as a characteristic that qualified people for admission to the program. 
A third criterion for admission to the program was a lack of adequate psychosocial supports. This criterion was most clearly linked to the need to prioritize admissions because of the limited program capacity. Participants identified a range of issues that should be considered, including homelessness or risk for homelessness, inadequate income, and lack of community support. Many clients indicated that at the time of their admission to the program, they required assistance with basic needs such as finding housing, income, and employment.

\section{IS THE COURT OUTREACH PROGRAM BEING IMPLEMENTED AS PLANNED?}

This section examines the implementation of various components of the Court Outreach Program. Two kinds of data are presented. First, we present quantitative data describing the services that were provided to the group of clients who had terminated their participation in the program $(n=50)$. The second kind of data comes from focus groups with staff members and key informants. The qualitative data report on perceptions of the implementation of the various components of the program.

\section{Quantitative Findings}

Type of services delivered. In line with eligibility criteria for the program, $98 \%$ of clients received mental health services and $94 \%$ received assistance with legal matters. As well, $90 \%$ of clients received services for housing and social network difficulties, and $80 \%$ received services targeting financial problems. Clients also received services related to physical health (56\%), substance abuse (52\%), vocational planning $(36 \%)$, educational planning (24\%), and recreational activities $(22 \%)$. Thus, in keeping with the program model, clients are provided with a wide range of community-based supports, in addition to legal support.

\section{Qualitative Findings}

Referral and assessment. The participants agreed that the need for the Court Outreach Program exceeds the program's capacity. CMHA managers reported that, as a result, there may be an "underreferral" of individuals to the program. Typically, referred individuals are perceived as having the greatest need in terms of mental health problems and a lack of psychosocial supports.

Various challenges were identified in the assessment process. One challenge stemmed from the difficulties clients face in understanding why they are being assessed. In other cases it was difficult to engage and assess clients who were not very communicative or who were evasive about their needs. Additionally, court outreach workers described challenges in assessing the mental health of clients due to the limited information available to them and their limited contact with clients.

Client-centred support. A key issue discussed by CMHA staff was the program philosophy. They emphasized the importance of delivering services according to particular values and principles. These included using a holistic approach to "address the whole person." They also emphasized the value of service provision that adhered to a client-centred recovery philosophy, and that aimed to "prevent future suffering, pain, and problems." Advocacy was a key element in this approach to services. According to CMHA staff, the program was based on the assumption that a person "has a right to treatment, and that we'll work from 
what the client's wants and desires are." Clients and family members noted feeling greatly supported by the Court Outreach Program workers. They indicated that the workers were able to meet clients where they were at in terms of their current levels of need in a number of domains.

An integrated approach. Participants described an integrated program delivery approach within CMHA and the court. Some of the key informants described the process and team as being "multidisciplinary." CMHA staff and court personnel were characterized as working together in a "symbiotic relationship" in which they shared information with one another.

Access to a range of supports. According to the CMHA staff, a main program goal is to divert people with severe mental illness from the court to community support and treatment. CMHA staff members emphasized that access to the full range of CMHA services was a necessary part of court outreach, and facilitated the referral of clients from the court system. One CMHA manager stated that "right from the beginning we give them [the clients] everything the agency offers." Another said, "Overall, it's about getting people with severe mental illness the support they need." Court outreach workers pointed to the importance of addressing housing and other support needs. As well, individuals may require being reconnected to services such as to previous case managers. The program also assists people in reconnecting with their family members and "getting back into the community."

According to the court outreach workers, challenges can arise from working with various community partners and other systems. They reported challenges with inflexible community start-up benefits and other programs' rejecting or banning their clients. Staff members cited barriers for their clients from mainstream services that do not accept people with histories of behavioural problems.

Legal support. Legal support refers to ensuring that clients receive help navigating the legal system, that they are informed of the options available to them, and that they are reminded of and attend court and probationary meetings. One key informant described this process as "accompaniment," which is the "sideby-side support of the person as he/she moves through the system." This key informant also stated the court procedures are "very confusing for the average person, and perhaps 10 times so for a person with mental health issues." According to a CMHA manager, "the court is a very passive — oddly enough — system, and it's not particularly well designed for people who can't remember appointments or who aren't organized."

Clients noted that Court Outreach Program workers were helpful in advocating for them within the legal system by assisting them with maintaining the conditions of probation and sentences as well as ensuring that they attended court dates. One family member indicated that workers helped the family to understand the legal system, which in turn helped them better support their family member. The knowledge and experience of the CMHA court outreach workers benefited non-program clients and staff who relied on their legal expertise and advice.

Key informants described how the CMHA workers assist with bail and case resolutions and how they are "quite efficient in bringing lawyers in touch with their client" especially in bail, pleas, and re-man court. In conjunction with taking clients to and from court appointments and trials, workers also advocate for and assist with other services, such as legal aid. One key informant stated that when CMHA is involved, "judges have the feeling that people with severe mental illness will be taken care of." CMHA staff members stated 
that the workers and the Court Outreach Program provided support not only to clients but also to lawyers and others in the legal system, as well as to other CMHA staff.

\section{WHAT ARE THE STRENGTHS AND WEAKNESSES OF THE COURT OUTREACH PROGRAM?}

\section{Program Strengths}

In terms of program strengths, participants listed features such as the program operation, the staff, the program's reputation, partnerships, and its various outcomes. CMHA managers listed qualities such as "flexibility," "rapid response," and "accessibility to portable services" as strengths of the program. According to the CMHA managers, the program staff members were well trained and professional and had a good understanding of the court system. Program strengths were also linked to the range of services offered to clients. One manager stated, "We're giving them what they want, in that we're helping them traverse the court system, but right from the beginning we give them everything the agency offers." Court outreach workers cited "user-friendl[iness]" and mobility as main assets.

Other CMHA staff members cited the court outreach workers as program strengths. They referred to the court outreach workers as "specialists" or "experts" who save them a lot of time and provide them with invaluable support. CMHA staff also identified the visibility of the CMHA at the courthouse and the increased number of outreach workers as a strength and valuable time saver: "They've increased the CMHA workers at the courthouse, there's somebody there all the time, or there appears to be. So I can just call down there instead of me going all the way down there.... It's a good resource to have somebody, or workers just at the courthouse itself."

The majority of the key informants were also pleased with the Court Outreach Program and identified many strengths, including "flexibility" and "accessibility" combined with "compassion," "dedication and commitment [to clients]," "competence," and "patient workers." Some noted that the court outreach workers understood the court process and the client population very well. One key informant noted that court outreach workers "are successful at rescuing people who have completely fallen from status or stability and gone through the proverbial cracks, and gotten into criminal trouble."

In general, the clients were satisfied with the court outreach workers and with the services they received. They noted that a program strength was the assistance they received with their appointments, either in the form of transportation or just having "someone to be there." Many clients mentioned the importance of having "someone to talk to," "someone who will listen," and "someone to be in touch with." One client in particular said, "[my worker] supported me and made me feel like I'm worth something."

According to family members, the strengths of the program included access to support and knowledge that provided peace of mind. For example, one family member stated that the "phone line was always open" and that they could get in touch with a worker easily. Another family member mentioned that their "worker had a good knowledge about mental illness." Finally, one family member talked about the peace of mind that the program brought to the family, and commented that it "takes stress off the family" to know their relative is supported. 


\section{Program Weaknesses}

Staff cited bottlenecks in referrals and assessments as program challenges. For example, one court outreach worker noted that "people have to wait for assessments, assessment beds, or are held in [detention] for no reason." Some key informants also identified issues with screening and assessments, and observed that the program could not serve everyone who could benefit from it. One key informant commented on these "restrictions" saying, "Screening [is] very important, but it leaves a lot of other people without support."

Other challenges were related to housing resources, feedback to the legal system from the program, and insufficient funding for the Court Outreach Program. Some participants identified the need for more housing resources for clients. Key informants identified the need for more feedback to legal system personnel on how well the program was functioning and on outcomes for clients. Finally, most participants called for increased funding for the program to increase its capacity.

For the clients, a critical issue was the amount of time spent with their workers. The majority of clients felt that workers did not spend enough time with them. However, the clients mentioned that even if the worker could not meet with them, the worker would phone them. Family members did not identify any weaknesses. In response to this question, one family member said, "That's hard-I don't think there are [any weaknesses]."

\section{DISCUSSION}

This study evaluated a novel program considered critical to the systems enhancement of community mental health targeted by the Ontario Ministry of Health and Long-Term Care. The research on court-based mental health programs has been characterized as being at an early stage of development (Hartford et al., 2007). The contribution of this study is that it provides a detailed evaluation of a particular type of courtbased support program that is becoming increasingly prevalent in community mental health systems (Dewa et al., 2008). In this section we discuss our key findings. We highlight both the unique contributions and the unique challenges of the Court Outreach Program. Then, we make recommendations for improving the implementation of this and similar programs. The recommendations come from the evaluation participants themselves, as well as from our own analyses and observations.

\section{Assessment of Program Implementation}

The findings identify the typical client of the Court Outreach Program as a younger, single male with a psychotic illness who is facing multiple charges. These findings are consistent with those from the Matryoshka Project that examined client characteristics in six programs across the province (Dewa et al., 2008). These findings are also consistent with the intended program clientele.

The evaluation participants agree that most of the clients who are referred and admitted to the program fit the program criteria. There appears to be two factors that contribute to this fit: a formal and an informal filtering process. The formal filtering process occurs during the intake and assessment process conducted by the CMHA court outreach worker. The informal filtering process, in contrast, is attributable to the perceptions of court personnel of both the program's criteria and the program's capacity. Issues related to program capacity were also identified in the Matryoshka Project (Dewa et al., 2008). 
It appears that individuals who are perceived by court personnel as having less need for services or who already receive some support, and who have fewer or less serious charges, are not referred to the program because it is assumed to be at full capacity. It is likely that clients who have more subtle mental health challenges or problems that are less troublesome for the legal system to manage are not referred to the program for a formal evaluation. It is worth investigating in future research the extent to which this informal filtering process may prevent women, older people, or people experiencing non-psychotic illness from benefiting from such a program. This is a significant issue for the judicial and mental health systems given the high number of individuals with mental health problems in the judicial system who are not currently receiving any mental health services (Blackburn, 2004).

Perhaps adding to the perception that the program is at its capacity is the bottleneck in the assessment process. A sole intake/assessment worker does not appear to be sufficient to keep up with the demands for assessments. From the perspective of the legal system, the program might appear non-responsive.

The Court Outreach Program appears to be offering a program in line with current interests in recoveryoriented and person-centred services. The environment in which the program operates, however, presents some challenges to this mode of service delivery. Court outreach workers meet clients in noisy environments, and clients may be unaware why they are meeting the worker. These initial meetings can present challenges to client engagement that make client-directed support difficult to achieve.

One of the apparent strengths of the program, that also appears to enhance its credibility in the legal system, is the range of supports offered. CMHA Ottawa is a large community-based mental health agency that provides a range of services needed by this clientele. Providing access to wide range of supports is consistent with the program model and also with the implementation of similar programs in Ontario (Dewa et al., 2008). It is notable that the CMHA staff reported difficulties gaining access to services or supports not available in-house for their clients. The lack of community resources beyond regular generic services available for people with severe mental illness is a significant obstacle for court support programs to be effective (Hartford et al., 2007).

A final observation is that the court outreach workers represent a unique source of knowledge and expertise that straddles the mental health and legal systems. This finding echoes findings from the Matryoshka Project in which court case managers were consulted by colleagues in both systems (Dewa et al., 2008). In the legal system, court outreach workers reported being frequently called upon for mental health-related consultation and advice by court personnel. Similarly, they reported providing consultation and advice to their colleagues in the mental health system about aspects of the legal system that may affect clients. Unfortunately, there is little research and best practices literature that directly addresses this unique role and, consequently, little information upon which to develop training for staff of new or existing programs (Blackburn, 2004).

\section{Recommendations}

Based on findings from this evaluation of the implementation of this program, we make the following recommendations for improvement.

\section{Improve access to information, and provide more resources and services}

Participants in this evaluation noted the need for more information, resources, and services in a number of areas. There appears to be a need to increase access to information among all stakeholders in the program. 
CMHA staff members would benefit from access to better information from the legal system about clients or potential clients. The key informants from the legal system identified the need for more information on the capacity of the program, as well as updates on the successes of the program to justify not only sustained and increased program funding but also their continued support of the program through referrals.

It also clear that the program requires more resources to accommodate more clients. There appears to be an informal triage of clients referred to the program by court personnel. Given the perceived limited resources of the program, not all who could benefit from the program are referred to it. Finally, there is a perceived need for greater community resources to which Court Outreach Program clients can be referred. Identified needs include housing, recreational and vocational services, family support, and treatment for drug and alcohol abuse. Gaining access to these resources requires not only increased collaboration among local partners, but also the initiative of regional and provincial funders and policy-makers to create the appropriate incentives or direction to ensure that these clients are accommodated.

\section{Increase staff, decrease workload}

A common recommendation from all participants was the need for more program staff. In particular, there was a need to increase the intake capacity. Moreover, an increase in staff size would give court outreach workers more time to provide support and consultation to both legal system personnel and other CMHA staff members whose clients come in contact with the legal system. This aspect of the work performed by court outreach staff is underrecognized. It is important to acknowledge the unique mental health and legal expertise that these outreach workers have acquired and how this expertise is used to benefit both the legal and mental health systems in a myriad of ways.

\section{Provide specific training and education}

More broadly, there seems to be a need for more education and awareness about mental illness in the court system. Legal personnel need more information about the CMHA and the Court Outreach Program, and how these services operate. This is especially important to avoid misconceptions and unrealistic expectations. There is also likely some additional training and support that could benefit the court outreach workers. This training could focus on communicating with clients and more effectively engaging them under these difficult circumstances.

\section{Create and disseminate more knowledge about court outreach programs}

A final recommendation concerns the need for more research and evaluation of court outreach programs to create and disseminate knowledge and to identify best practices. As we have noted, the court outreach workers occupy unique positions and have unique knowledge of benefit to both the legal and mental health systems. These programs remain relatively underevaluated and underresearched, particularly in Canada, and a wide variety of program models exist (Hartford et al., 2007; Steadman et al., 1995). Of value would be making a concerted effort to systematically gather information that could contribute to a best practices literature to guide the refinement of existing programs and the development of new ones. This initiative would require further investment and support by regional, provincial, and federal funders. 


\section{CONCLUSION}

Court Outreach Programs are critical interventions to divert people with serious mental illness from incarceration to essential community support and treatment programs. These programs can help to combat the criminalization of this vulnerable population by ensuring that individuals gain access to services and resources to help them become more stabilized and integrated in community life. Programs such as this one, however, will remain hindered by community mental health systems that remain underfunded and lack integration. Moreover, this unique population may also suffer from additional challenges due to stigma and discrimination within existing service systems and the broader community. Ultimately, the success of these programs lies not only in how well they are implemented, but also in how well they are understood and supported by regional and provincial leaders, policy-makers, funders, and practitioners in the mental health and judicial systems.

\section{RÉSUMÉ}

Dans cet article, nous décrivons la mise en place du Court Outreach Program, offert par la filiale d'Ottawa de la Canadian Mental Health Association. Il s'agit d'un programme d'aide juridique qui offre du soutien et des soins en milieu communautaire aux personnes ayant des problèmes de santé mentale et qui font affaire avec le système judiciaire. L'une des forces du programme est son personnel compétent qui connaît bien les systèmes judiciaire et de santé mentale, et qui offre l'accès à du soutien et à différents traitements en milieu communautaire. Parmi ses faiblesses, notons sa capacité limitée à servir la clientèle potentielle, et des goulets d'étranglement au niveau du processus d'accueil et d'évaluation. Nous faisons des recommandations pour améliorer le programme.

\section{REFERENCES}

Blackburn, R. (2004). "What works" with mentally disordered offenders. Psychology, Crime, \& Law, 10, 297-308. Boccaccini, M.T.P.D., Christy, A.P.D., Poythress, N.P.D., \& Kershaw, D.P.D. (2005). Rediversion in two postbooking jail diversion programs in Florida. Psychiatric Services, 56, 835-839.

Christy, A., Poythress, N.G., Boothroyd, R.A., Petrila, J., \& Mehra, S. (2005). Evaluating the efficiency and community safety goals of the Broward County Mental Health Court. Behavioral Sciences and the Law, 23, 227-243.

Dewa, C.S., Chau, N., deRuiter, W., Loong, D., Trojanowski, L., \& Yip, A. (2008). Wave 3 report: Court support programs. Toronto, ON: Ontario Ministry of Health and Long-Term Care, Systems Enhancement Evaluation Initiative.

Draine, J., Blank, A., Kottsieper, P., \& Solomon, P. (2005). Contrasting jail diversion and in-jail services for mental illness and substance abuse: Do they serve the same clients? Behavioral Sciences and the Law, 23, 171-181.

Hartford, K., Carey, R., \& Mendonca, J. (2007). Pretrial court diversion of people with mental illness. Journal of Behavioral Health Services and Research, 34, 198-205.

Hartford, K., Davies, S., Dobson, C., Dykeman, C., Furhman, B., Hanbidge, J., . . Vandervooren, J. (2004). Evidencebased practices in diversion programs for persons with serious mental illness who are in conflict with the law: Literature review and synthesis. London, ON: Lawson Health Research Unit, University of Western Ontario.

Lattimore, P.K., Broner, N., Sherman, R., Frisman, L., \& Shafer, M.S. (2003). A comparison of prebooking and postbooking diversion programs for mentally ill substance-using individuals with justice involvement. Journal of Contemporary Criminal Justice, 19, 30-64.

Ontario Federation of Community Mental Health and Addiction Programs. (1999). Canadian version IAPSR PSR toolkit. Toronto, ON: Author.

Redlich, A.D., Steadman, H.J., Monahan, J., Robbins, P.C., \& Petrila, J. (2006). Patterns of practice in mental health courts: A national survey. Law and Human Behavior, 30, 347-362. 
Rossi, P.H., Lipsey, M.W., \& Freeman, H.E. (2004). Evaluation: A systematic approach (7 ${ }^{\text {th }}$ ed.). Thousand Oaks, CA: Sage.

Steadman, H., Barbera, S., \& Dennis, D. (1994). A national survey of jail mental health diversion programs. Hospital and Community Psychiatry, 45, 1109-1112.

Steadman, H.J., Morris, S.M., \& Dennis, D.L. (1995). The diversion of mentally ill persons from jails to communitybased services: A profile of programs. American Journal of Public Health, 85, 1630-1635.

Strauss, A.L. (1987). Qualitative analysis for social scientists. New York: Cambridge University Press.

Swaminath, R.S., Mendonca, J.D., Vidal, C., \& Chapman, P. (2002). Experiments in change: Pretrial diversion of offenders with mental illness. Canadian Journal of Psychiatry, 47, 450-458. 